\title{
LOCKED NAILING FOR NONUNION OF THE TIBIA
}

\author{
J. W. ROSSON, R. B. SIMONIS
}

From St Peter's Hospital, Chertsey

\begin{abstract}
We treated 24 patients with nonunion of tibial shaft fractures by locked intramedullary nailing, 18 by open and six by closed techniques. Union was achieved in 22 patients, failing only in two patients with active infection. Locked nailing prevented recurrence of deformity and allowed the patients to mobilise without external support. Supplementary bone grafting was essential only for major defects.
\end{abstract}

Failure of union of a fracture of the tibial shaft may be influenced by the nature of the fracture, the severity of associated soft-tissue injury, concurrent systemic disease and the method of treatment. With appropriate primary treatment the incidence of nonunion should become minimal, but the problem is still relatively common. A number of methods of stimulating union after early failure have been described. These include fibular osteotomy followed by weight-bearing in a cast, autogenous bone grafting with or without additional stabilisation, internal or external fixation with compression, open or closed intramedullary nailing and even electromagnetic stimulation (Jones and Barnett 1955; Olerud and Karlström 1972; Christensen 1973; Freeland and Mutz 1976; Bassett, Mitchell and Gaston 1981; DeLee, Heckman and Lewis 1981 ; Clancey, Winquist and Hansen 1982).

We report the use, since 1987, at a secondary referral centre, of the Grosse Kempf interlocking nail for a consecutive series of 24 such patients.

\section{PATIENTS AND METHODS}

The details of the 24 patients are given in Table I. Fourteen had originally had closed fractures. All cases had been referred from other hospitals, often many months after injury, and it proved impossible to grade the ten open fractures. The mean interval between fracture and secondary surgery was 20 months (10 to 54).

Six patients had been treated by closed methods alone, including os calcis traction and plaster. The other 18 patients had had a total of 28 previous operations. External fixators had been used in ten of these, plates in

J. W. Rosson, MS, FRCS, Senior Orthopaedic Registrar R. B. Simonis, FRCS, Consultant Orthopaedic Surgeon

Rowley Bristow Orthopaedic Unit, St Peter's Hospital, Chertsey, Surrey KT16 0PZ, England.

Correspondence should be sent to Mr R. B. Simonis.

(C) 1992 British Editorial Society of Bone and Joint Surgery 0301-620X/92/3348 \$2.00

J Bone Joint Surg [ Br] 1992; 74-B: 358-61. nine and an intramedullary nail in one. Two of the patients had nonunion at the site of a corrective osteotomy, performed for previous malunion.

Nailing. In 18 patients the operation was open and in six it was closed although two also had open removal of a tibial plate. A fibular osteotomy was performed in all cases through a separate lateral incision at the beginning of the operation. Closed nailing was performed under radiographic control in the conventional manner.

In all 18 open procedures, the limb was exsanguinated and a thigh tourniquet applied after administration of prophylactic antibiotics. The tibia was then approached through an anterior longitudinal incision, the periosteum was elevated together with slivers of cortical bone, using an osteotome, and fibrous tissue was excised from the fracture site. The medullary cavity was opened on both sides of the fracture with a drill and any deformity corrected.

A longitudinal patellar tendon-splitting incision exposed the upper tibia and a guide wire was introduced. The medullary canal was then reamed to an appropriate diameter under radiographic control and a nail of appropriate length, of as large a diameter as possible, was introduced and locking screws inserted. All bone reamings were saved and applied around the fracture site. No additional bone graft was used.

The wounds were closed in layers over suction drains and the patients remained in bed with the limb elevated for ten days until the sutures had been removed.

Eleven of the nails were locked dynamically with screws only in the smaller tibial fragment; 13 were statically locked with screws both proximally and distally. In ten of these patients, the nails were dynamised after two to three months by removal of the locking screws from the larger fragment. A substantial defect was present at the fracture site at the end of the procedure in three patients (cases 14, 20 and 23). In these patients static locking was maintained until there was radiographic evidence of incorporation of bone graft with partial weight-bearing only. Except for these three 
Table I. Details of 24 patients treated for nonunion of tibial shaft fractures

\begin{tabular}{|c|c|c|c|c|c|c|}
\hline Case & $\begin{array}{l}\text { Age } \\
\text { (yr) }\end{array}$ & $\begin{array}{l}\text { Fracture } \\
\text { level }\end{array}$ & $\begin{array}{l}\text { Number of } \\
\text { previous } \\
\text { operations }\end{array}$ & $\begin{array}{l}\text { Months from } \\
\text { original } \\
\text { injury }\end{array}$ & $\begin{array}{l}\text { Type of } \\
\text { nonunion }\end{array}$ & $\begin{array}{l}\text { Time to union } \\
\text { (mth) }\end{array}$ \\
\hline 1 & 36 & Middle* & 2 & 39 & Atrophic & 5 \\
\hline 2 & 27 & Distal* & $\overline{1}$ & 13 & Atrophic & 3 \\
\hline 3 & 62 & Middle* & 1 & 11 & Atrophic & Failed \\
\hline 4 & 26 & Middle & 2 & 24 & Hypertrophic & 2 \\
\hline 5 & 36 & Proximal & 1 & 24 & Hypertrophic & Failed \\
\hline 6 & 39 & Distal $^{*}$ & 0 & 10 & Hypertrophic & 3 \\
\hline 7 & 23 & Distal* & 2 & 20 & Hypertrophic & 2 \\
\hline 8 & 23 & Middle* & 1 & 13 & Hypertrophic & 3 \\
\hline 9 & 35 & Distal & 0 & 35 & Hypertrophic & 6 \\
\hline 10 & 28 & Middle & 1 & 10 & Hypertrophic & 6 \\
\hline 11 & 36 & Segmental & 1 & 15 & Hypertrophic & 4 \\
\hline 12 & 77 & Middle* & 0 & 16 & Atrophic & 4 \\
\hline 13 & 22 & Distal & 2 & 20 & Atrophic & 9 \\
\hline 14 & 33 & Distal ${ }^{*}$ & 2 & 54 & Atrophic & 12 \\
\hline 15 & 30 & Distal ${ }^{*}$ & 0 & 11 & Hypertrophic & 4 \\
\hline 16 & 52 & Distal & 1 & 12 & Atrophic & 12 \\
\hline 17 & 24 & Distal & 2 & 19 & Hypertrophic & 12 \\
\hline 18 & 21 & Distal & 2 & 41 & Hypertrophic * & 3 \\
\hline 19 & 22 & Distal & 3 & 31 & Hypertrophic & 8 \\
\hline 20 & 22 & Distal & 1 & 36 & Atrophic & 13 \\
\hline 21 & 21 & Distal* & 0 & 14 & Hypertrophic & 3 \\
\hline 22 & 23 & Distal & 0 & 12 & Atrophic & 8 \\
\hline 23 & 26 & Middle & 2 & 21 & Atrophic & 14 \\
\hline 24 & 23 & Proximal* & 1 & 12 & Atrophic * & 15 \\
\hline
\end{tabular}

* closed fracture, closed nailing
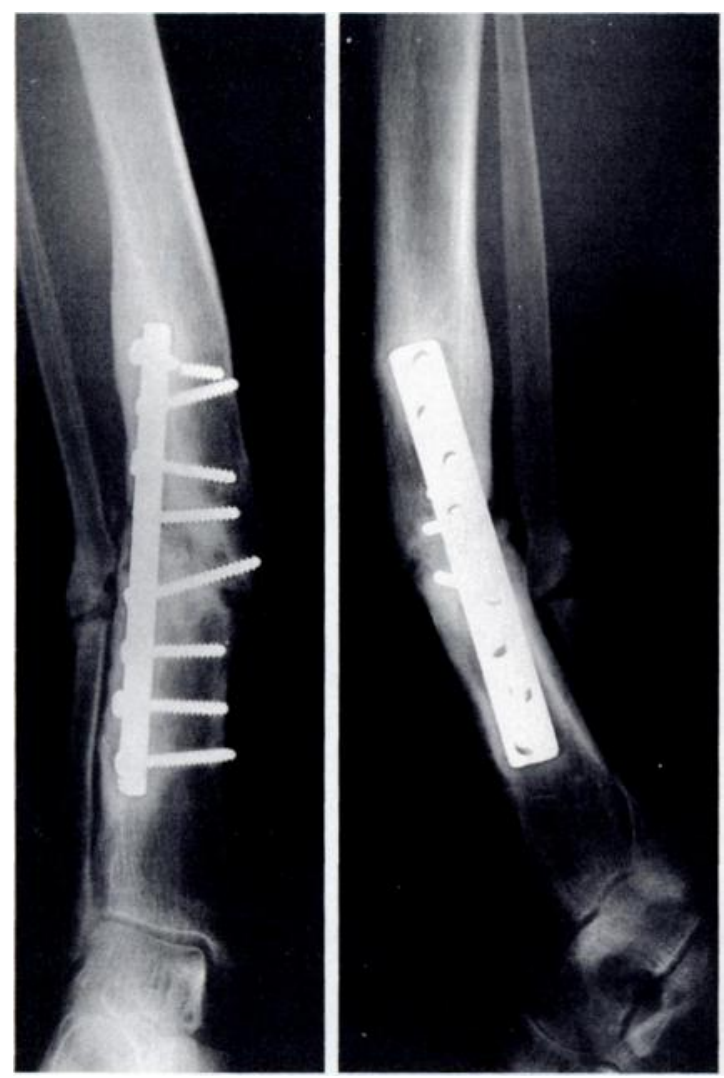

Fig. 1

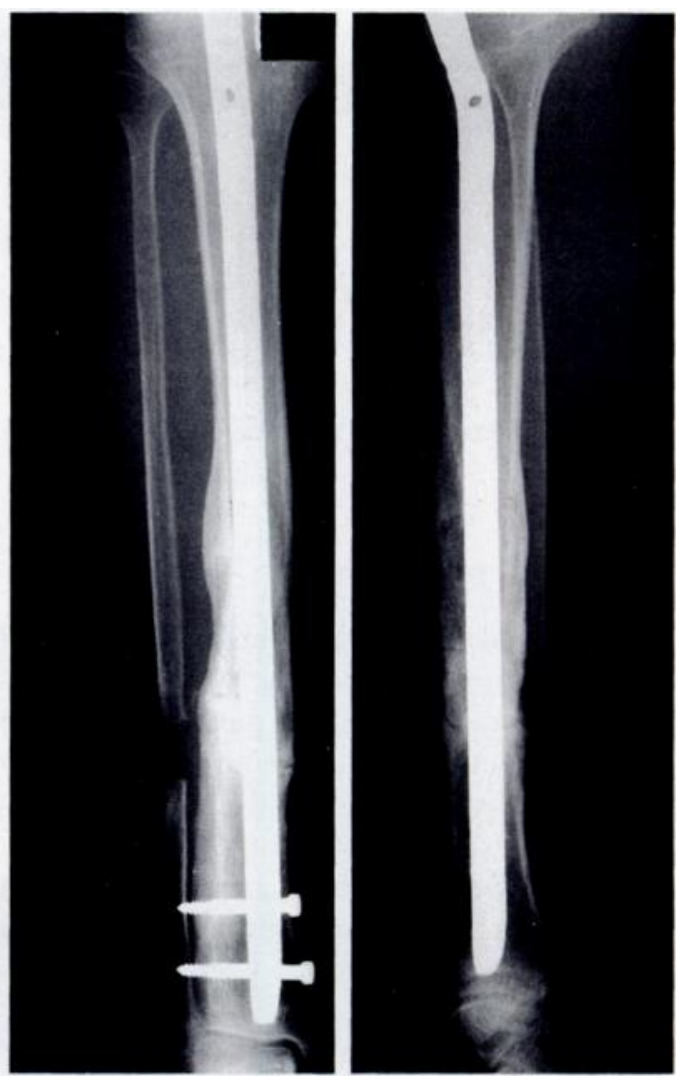

Fig. 2

Case 13. Figure 1 - Nonunion after plate fixation. Figure 2 - Ten months after open nailing. 

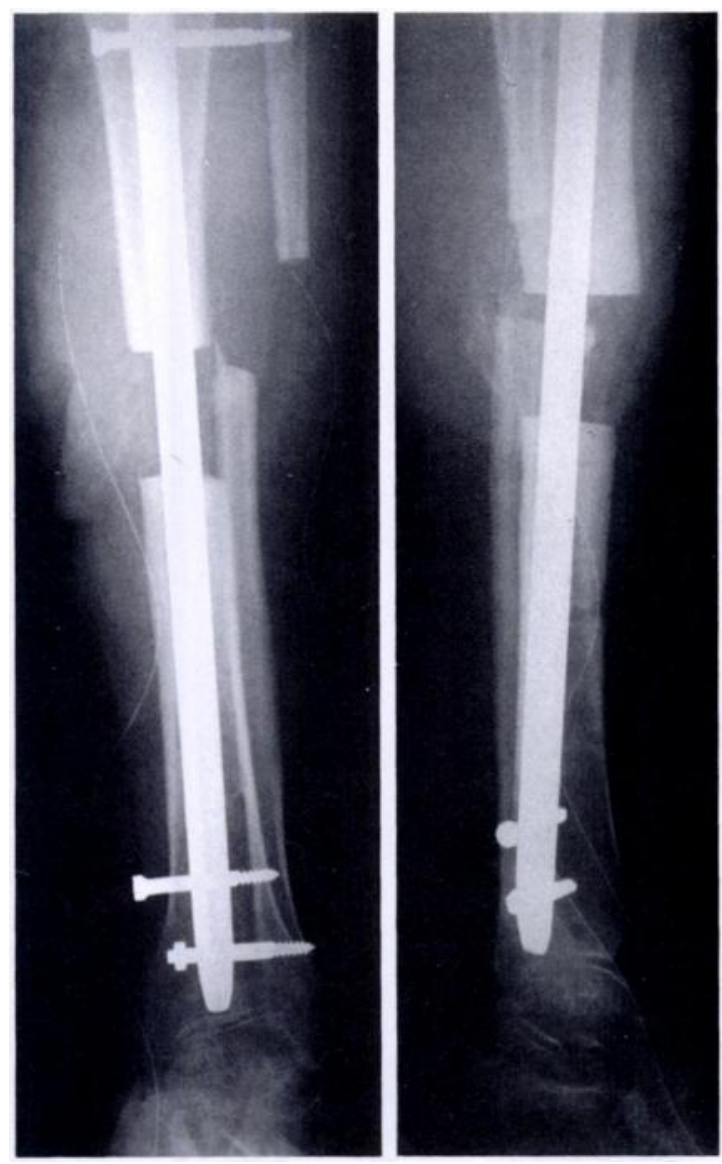

Fig. 3
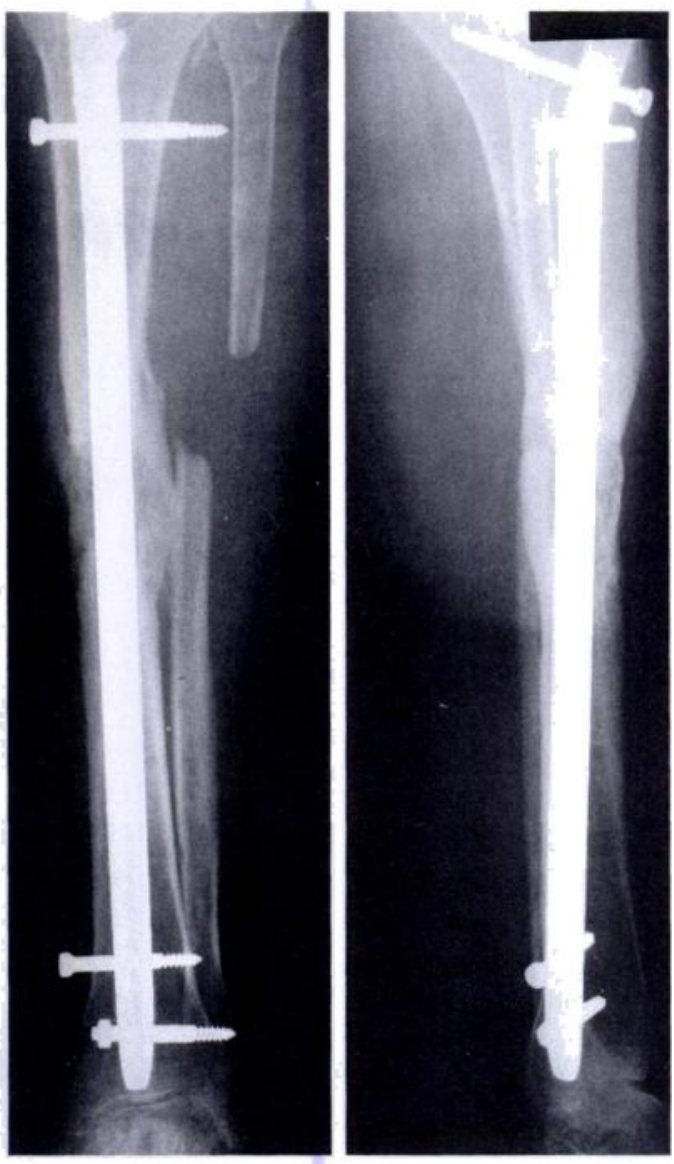

Fig. 4

Case 14. Figure 3 - Appearance after open nailing and removal of avascular bone. Figure 4 - Sixteen months after autogenous cancellous bone grafting.

patients, full weight-bearing was allowed with no external protection of the limb.

\section{RESULTS}

Angular and rotational deformities were corrected in all patients but pre-existing shortening was unchanged. Union was obtained in 22 of the 24 patients (Table I). The mean interval between surgery and radiographic union was nine months ( 2 to 15, Figs 1 and 2), evidence of bone bridging the defect on four views of the tibia being required as proof of union. Clinical union with pain-free weight-bearing always preceded this radiographic confirmation, as reported by Olerud and Karlström (1972).

In three patients, the preservation of length after removal of a vascular bone resulted in a substantial defect at the fracture site; all these cases needed autogenous bone grafting before union was achieved (Figs 3 and 4).

In two patients there was overt sepsis at the time of surgery, and in both cases there was failure of union. One elderly man was taking azathioprine and prednisolone for a dermatological condition; his wound continued to drain, and at six weeks a decision was made to amputate. The second was a younger man seen 24 months after an open fracture. After three months of continued infection the nail was removed and a circular fixator was applied. Eventually this tibia united.

Four other patients, all with records of previous infection, developed superficial infection after nailing, all of which resolved with bedrest and antibiotics.

Loss of position of the fracture was seen in only one case, in which failure to lock statically resulted in increased shortening. Despite this error union occurred and the patient's mobility was improved.

\section{DISCUSSION}

The value of intramedullary stabilisation of ununited fractures of the tibial shaft has been reported (Clancey et al 1982), and the use of an open technique has been recommended by Johnson and Marder (1987), as permitting correction of deformity and allowing the inclusion of bone grafts. We prefer closed nailing when this is 
surgically possible. The advantage is that less trauma to the soft tissues leads to quicker recovery: only one of our six patients treated by closed methods had union delayed beyond six months. Of the 18 patients in whom correction of deformity could be achieved only by open surgery, 16 progressed to union. Our results, therefore, support the use of an open technique when necessary.

In contrast to previous reports, we used locked nails in all our patients; we believe that this has important advantages. Short fracture fragments, both proximally and distally, can be stabilised by the screws and therefore more patients are suitable for intramedullary fixation. The additional stability also prevents both rotation and further shortening, so that additional external support is not necessary. The open excision of enough fibrous tissue to allow correction of deformity, together with a fibular osteotomy, must destabilise the fracture; a locked nail can control this instability.

The position of the fracture deteriorated in only one patient because of failure to recognise that static locking was needed. Such locking is often necessary in the first instance, but we feel that subsequent dynamisation is desirable to increase the load through the fracture, except in patients with major defects requiring supplementary bone grafts.

In contrast to Johnson and Marder (1987), our initial bone grafting used only the products of intramedullary reaming. Three of our patients did require subsequent bone grafting, but all three had large defects (Fig. 3), and the use of a statically locked nail allowed us to maintain length. When there is a substantial defect, we now add supplementary autogenous bone at the time of the initial procedure.

Conclusions. Our experience of these 24 patients shows that the technique should not be used in the presence of sepsis. It confirms that intramedullary stabilisation is an excellent method of achieving union in the absence of sepsis. Locked nails prevent shortening and recurrence of deformity, and obviate the need for external support, allowing rapid rehabilitation.

Our current methods are:

1) routine fibular osteotomy;

2) closed nailing if technically possible;

3) for open nailing, exposure of the bone using Judettype decortication;

4) correction of malalignment with minimal resection of bone;

5) use of the maximum possible diameter of nail;

6) use of static locking, initially with dynamisation at two to three months; and

7) additional use of bone grafts only for major defects.

No benefits in any form have been received or will be received from a commercial party related directly or indirectly to the subject of this article.

\section{REFERENCES}

Bassett CAL, Mitchell SN, Gaston SR. Treatment of ununited tibial diaphyseal fractures with pulsing electromagnetic fields. $J$ Bone Joint Surg [Am] 1981; 63-A :511-23.

Christensen NO. Küntscher intramedullary reaming and nail fixation for non-union of fracture of the femur and the tibia. $J$ Bone Joint Surg $[\mathrm{Br}] 1973 ; 55-\mathrm{B}: 312-8$.

Clancey GJ, Winquist RA, Hansen ST. Non-union of the tibia treated with Küntscher intramedullary nailing. Clin Orthop 1982; 167: 191-6.

DeLee JC, Heckman JD, Lewis AG. Partial fibulectomy for ununited fractures of the tibia.J Bone Joint Surg [Am] 1981 ; 63-A :1390-5.

Freeland AE, Mutz SB. Posterior bone-grafting for infected ununited fracture of the tibia. J Bone Joint Surg [ Am] 1976; 58-A :653-7.

Johnson EE, Marder RA. Open intramedullary nailing and bonegrafting for non-union of tibial diaphyseal fracture. $J$ Bone Joint Surg [Am] 1987; 69-A :375-80.

Jones KG, Barnett HC. Cancellous-bone grafting for non-union of the tibia through the posterolateral approach. J Bone Joint Surg [Am] $1955 ; 37-\mathrm{A}: 1250-60$.

Olerud S, Karlström G. Secondary intramedullary nailing of tibial fractures. J Bone Joint Surg [Am] 1972; 54-A:1419-28. 